\title{
Dynamic Response of Parallel Overlapped Tunnel under Seismic Loading by Shaking Table Tests
}

\author{
Tao Yang $\left(\mathbb{D},{ }^{1}\right.$ Yunkang Rao $\mathbb{D}$, ${ }^{1}$ Honggang Wu $\mathbb{D},{ }^{2}$ Junyun Zhang $\mathbb{D},{ }^{1}$ Hao Lei $\mathbb{D},{ }^{3}$ \\ and Haojiang Ding (iD ${ }^{4}$ \\ ${ }^{1}$ School of Civil Engineering, Southwest Jiaotong University, Chengdu 610031, China \\ ${ }^{2}$ Northwest Research Institute Co., Ltd. of C.R.E.C, Lanzhou, Gansu 730000, China \\ ${ }^{3}$ School of Civil Engineering, Lanzhou Jiaotong University, Lanzhou, Gansu 730000, China \\ ${ }^{4}$ China Railway Eryuan Engineering Group Co. Ltd., Chengdu 610031, China
}

Correspondence should be addressed to Honggang Wu; 271462550@qq.com

Received 12 April 2021; Accepted 29 May 2021; Published 8 June 2021

Academic Editor: Honglue Qu

Copyright (c) 2021 Tao Yang et al. This is an open access article distributed under the Creative Commons Attribution License, which permits unrestricted use, distribution, and reproduction in any medium, provided the original work is properly cited.

Potential earthquake-induced damage to overlapped tunnels probably occurs during the operation and maintenance of mountain tunnel engineering, especially in the seismically active zone. This study investigated the dynamic response and the failure characteristics of the parallel overlapped tunnel under seismic loadings by employing shaking table tests. The failure mode of the parallel overlapped tunnels was analyzed through macroscopic test phenomena. The dynamic responses of the surrounding rock and tunnel lining were evaluated by acceleration and dynamic strain, respectively. In particular, wavelet packets were used to investigate the spectrum characteristics of the tunnel structure in depth. The failure process of the model can be divided into three stages. The upper-span and the under-crossing tunnels showed different failure characteristics. Additionally, the lining damage on the outer surface of the tunnel mainly occurred on the right side arch waist and the left side wall, whereas the lining damage on the inner surface of the tunnel mainly appeared on the crown and invert. Wavelet packet energy results showed that the energy characteristic distributions of the upper-span and the under-crossing tunnels were not consistent. Specifically, the energy eigenvalues of the crown of the upper-span tunnel and the invert of the under-crossing tunnel were the largest, which should be considered to be the weak parts in the seismic design.

\section{Introduction}

Earthquakes and rainfall are two important factors often considered in the studies of engineering structure stability [1, 2], and the structural dynamic response caused by earthquakes has been paid more attention. The overlapped tunnel has been widely used in engineering because of the limitation of terrain and route selection [3]. According to the relative relationship of space and structure in the cross tunnel, Li et al. and Liu et al. $[4,5]$ divided the cross tunnel into two types: structural cross and spatial cross. Moreover, the structural cross tunnel was divided into structural bifurcation, structural connection channel, and structural wind types; the spatial cross tunnel was divided into spatial orthogonal, spatial parallel, and spatial oblique types, as shown in Figure 1. As the traffic arteries pass through complex mountainous areas, more overlapped tunnels are built-in high-intensity earthquake areas, which often face the problems of earthquake damage [6]. Therefore, it is necessary to study the seismic response of overlapping tunnels in high-intensity earthquake areas.

In previous studies on overlapped tunnels, scholars mainly discussed the construction mechanical characteristics of overlapped tunnels and have already made some achievements in the statics of the cross tunnel in terms of the distribution of mechanical characteristics, reinforcement technology, and monitoring and measurement [7-17]. Some scholars have analyzed the mechanical characteristics and stability of the surrounding rock of the cross tunnel with a small clear distance through different numerical software; 


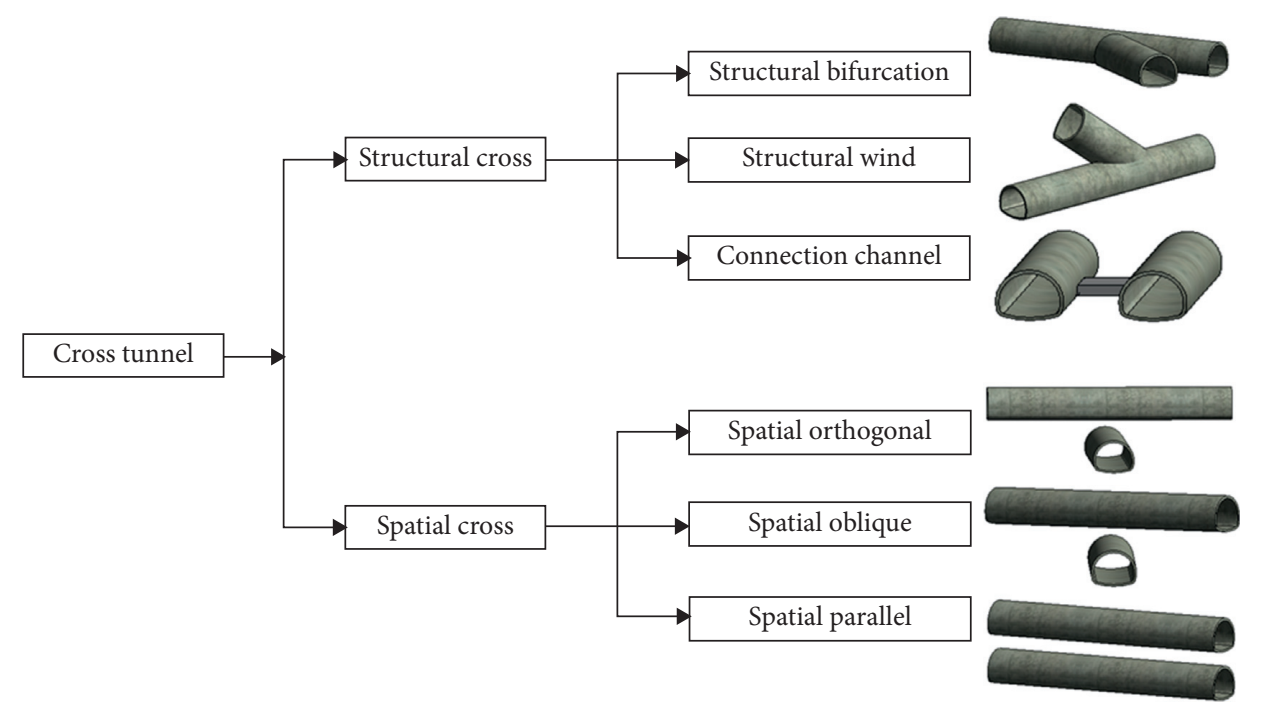

FIgURE 1: Classification of cross tunnels.

the results showed that the maximum displacement at the crown was caused by the construction disturbance and the release of the stress of the crown $[10,11]$. Liu et al. and Lin et al. $[12,13]$ conducted a theoretical analysis and numerical simulation study on the construction process of the overlapped subway tunnel with a small clear distance. They pointed out that when a new tunnel was constructed over the span, the additional stress generated was mainly concentrated in the original tunnel area at the intersection of the tunnel. Other scholars have put forward suggestions for the reinforcement of overlapped tunnels. For example, Zhang et al. and Liu et al. $[14,15]$ used compensation grouting to reinforce the rock column between the existing tunnel and the new tunnel to reduce the settlement of the existing tunnel. Furthermore, the strength of the surrounding rock and the existing tunnel can be improved together by controlling the specific grouting pressure. In terms of monitoring and measurement of overlapped tunnels, the superposition method was used to monitor the surface settlement of the existing tunnel and the new tunnel. Fang et al. and Jin et al. $[16,17]$ found that the settlement of the existing tunnel and the surface section shows different shapes; that is, the settlement of the existing tunnel section is in the shape of "W," whereas the settlement of the surface section is in the shape of "U."

Owing to the characteristics of multieffect coupling, load reciprocating superposition, and complex deformation of overlapped tunnels under dynamic loading, the degree and scope of structural damage are aggravated, which poses a great potential safety risk for the construction and operation of the overlapped tunnel [18]. At present, some scholars have studied the dynamics of the overlapped tunnel, mainly focusing on the effects of blasting vibration, train loading, and seismic loading $[19,20]$. The blasting excavation of overlapped tunnels has specific unique characteristics, which not only ensures that the original tunnel structure and support system will not be damaged during blasting but also considers the self-stability of surrounding rock after multiple vibrations [21]. Zhao et al. [22] used field monitoring tests and finite element numerical methods to study the blasting vibration velocity and frequency of existing tunnels. Moreover, they used different indicators to evaluate the impact of blasting during the construction of new tunnels.

Additionally, the vibration of long-term train load can cause damage and cracking of the tunnel structure and even cause severe damage to the tunnel lining, which is easy to cause large deformation of the structure and bring great hidden danger to the operation safety of the overlapped tunnel. Some scholars carried out field tests and model tests to study the effect of train loading and draw some valuable conclusions on the overlapped tunnel $[23,24]$. The overlapped tunnel structure will produce the superposition of seismic waves under the action of seismic loading, and the loading generated by the seismic effect is greater than the other two dynamic loadings, so it is often the most severely damaged under the action of seismic load [25]. Wu et al. and Lei et al. [26, 27] carried out shaking table tests to study the seismic response of orthogonal and oblique overlapped tunnels, respectively, and preliminarily discussed and analyzed the acceleration response and lining strain response of the upper-span and under-crossing tunnels.

Through the above studies, it is found that previous studies on the overlapped tunnel mainly focused on the static aspects such as construction mechanics. Although the dynamics of the overlapped tunnel have also made some progress, the dynamic response characteristics of the overlapped tunnel under seismic loading have not made a substantial breakthrough, and the study on the parallel overlapped tunnel is even less. To study the dynamic response and spectrum response of the parallel overlapped tunnel under seismic loadings, the dynamic damage of the tunnel lining and the acceleration response of the surrounding rock was analyzed through the shaking table tests. Additionally, the mathematical tool of wavelet packet was introduced to discuss the characteristics of seismic waves in the time-frequency domain. The results are expected to 
provide a theoretical reference for the response to the dynamic rationality study of this type of the overlapped tunnel.

\section{Shaking Table Tests}

2.1. Shaking Table System. This test used the RC-3000 vibration control system, which used a structure that directly integrates the LAN bus and the embedded DSP. Moreover, this system had a full range of one-way vibration test functions. The main technical parameters of this shaking table system are shown in Table 1 .

The shaking table system was equipped with a rigid model box with dimensions of $175 \mathrm{~cm}$ (length) $\times 30 \mathrm{~cm}$ (width) $\times 120 \mathrm{~cm}$ (height). The mainframe of the rigid model box was welded with $4080 \mathrm{~L}$ alloy aluminum material, as shown in Figure 2. To meet the requirements of rigidity and visual test, both sides of the inner side were made of $10 \mathrm{~mm}$ thick PP sheet to facilitate the observation of failure phenomena, and the inner side of the model box was a steel plate. The model box was rigidly fixed on the shaking table by surrounding bolts, which is a commonly used device for studying soil-structure dynamic characteristics in shaking table tests.

The rigid model box may cause errors in the test data due to the boundary effect [28]. Therefore, three measures were taken to deal with the boundary effect-caused errors: (1) to reduce the influence of the boundary effect, a $50 \mathrm{~mm}$ thick polystyrene foam board with a density of $15 \mathrm{~kg} / \mathrm{m}^{3}$ was used to paste the inner side of the model box to reduce the friction between the side wall of the model box and the soil. The polystyrene foam plastic board was always in a linear elastic state during the test loading process and had good compression properties (Dynamic elastic modulus $\mathrm{Ed}=4.13 \mathrm{MPa}$ ); (2) to reduce the reflection of waves on the boundary surface, a layer of polystyrene foam board was also laid on the two sides parallel to the tunnel; (3) to ensure good adhesion between the model soil and the bottom of the box, a layer of $5 \mathrm{~cm}$ thick gravel soil with the size of $1 \mathrm{~cm}$ was laid on the bottom of the model box to increase the friction; thus, the bottom plate was treated as a friction boundary to limit the relative displacement between the bottom of the box and the soil. The effectiveness of the above treatment of the boundary effect of the model box has been verified in previous experiments [26].

2.2. Design and Construction of the Model. Taking into account the size of the shaking table model box and the possible application of this model in some actual construction projects, this experiment used the geometric similarity ratio $C_{\mathrm{L}}$ of 100 to design the tunnel combined with the previous tunnel construction practice of relevant specifications [29]. Taking geometry, density, and acceleration as the basic physical parameters, the geometric similarity ratio was determined to be $1: 100$; the similarity ratios of density and acceleration were both $1: 1$; the similarity ratios of other physical quantities were derived based on the Buckingham $\pi$ theorem [30], as shown in Table 2.
TABLe 1: Parameters of shaking table system.

\begin{tabular}{lc}
\hline Parameters & Technical specification \\
\hline Table size $(\mathrm{m})$ & $3 \times 2$ \\
Loading direction & Horizontal $(X)$ \\
Working frequency $(\mathrm{Hz})$ & $0.2 \sim 50$ \\
Maximum load $(\mathrm{t})$ & 0.5 \\
Maximum acceleration $(\mathrm{g})$ & 1.0 \\
Maximum overturning moment $(\mathrm{kN} \cdot \mathrm{m})$ & 10 \\
Maximum eccentric moment $(\mathrm{kN} \cdot \mathrm{m})$ & 5 \\
Maximum velocity $(\mathrm{m} / \mathrm{s})$ & 2 \\
Maximum displacement $(\mathrm{mm})$ & 51 \\
\hline
\end{tabular}

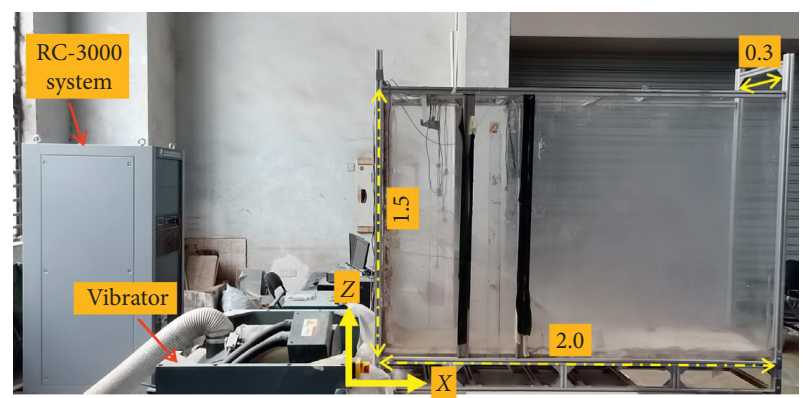

FIGURE 2: Shaking table system and model box (unit: m).

The selection of model materials was mainly based on previous study [29]. The parameter preparation was carried out according to the Chinese criterion "Code for Design of Highway Tunnels (JTG 3370.1-2018)" taking the IV grade surrounding rock as an example. According to the model design parameters and the test results of multiple sets of materials, it was finally determined that quartz sand was the main material; gypsum powder and talc powder were used as auxiliary materials; and red clay, cement, and water were used as bonding materials. The sample test process is shown in Figure 3. The specific similar parameters are shown in Table 3. Moreover, in the process of the test, considering that the earthquake may induce a landslide, which may affect the dynamic response of the tunnel structure, the sliding surface was set in advance in the model design.

The lining section of the tunnel adopted the standard section of the three-lane highway composite tunnel lining at a speed of $120 \mathrm{~km} / \mathrm{h}$, with a design grade of C30 and thickness of $60 \mathrm{~cm}$. Additionally, the lining model, which was mainly made by mixing gypsum powder and water in a certain proportion, had a maximum span of $19.3 \mathrm{~cm}$, a height of $14.6 \mathrm{~cm}$, and a thickness of $0.6 \mathrm{~cm}$ according to the geometric similarity. Furthermore, the steel wire mesh with a diameter of $0.2 \mathrm{~mm}$ was used to approximate the circumferential main reinforcement and distributed reinforcement in the lining structure, as shown in Figure 4.

During the model filling process, similar materials were filled into the model box with a layer of $10 \mathrm{~cm}$ thick by layered filling. Moreover, each soil layer was compacted in the same way to ensure that the model was filled evenly. During the filling of the similar materials, acceleration sensors and strain gauges were arranged, as shown in Figures 5(a) and 5(b). 
TABLE 2: Similarity relations and ratios.

\begin{tabular}{lccc}
\hline & Physical parameters & Symbol and relational expression & Similarity ratio \\
\hline \multirow{2}{*}{ Geometric parameters } & Length $(L)$ & $C_{L}$ & $1 / 100$ \\
& Linear displacement $(x)$ & $C_{x}=C_{L}$ & $1 / 100$ \\
\hline & Density $(\rho)$ & $C_{\rho}$ & 1 \\
& Stress $(\sigma)$ & $C_{\sigma}=C_{E}$ & $C_{\varepsilon}$ \\
Material parameters & Strain $(\varepsilon)$ & $C_{\mu}$ & $1 / 100$ \\
& Poisson's ratio $(\mu)$ & $C_{\phi}$ & 1 \\
& Internal friction angle $(\phi)$ & $C_{c}=C_{E}$ & $1 / 100$ \\
& Cohesion $(c)$ & $C_{E}=C_{L} C_{a} C_{\rho}$ & $1 / 100$ \\
\hline \multirow{5}{*}{ Dynamic parameters } & Elastic modulus $(E)$ & $C_{a}$ & 1 \\
& Acceleration $(a)$ & $C_{f}=C_{L}^{-1 / 2} C_{a}^{1 / 2}$ & $1 / 0.1$ \\
& Frequency $(f)$ & $C_{v}=C_{L}^{1 / 2} C_{a}^{1 / 2}$ & $1 / 10$ \\
\hline
\end{tabular}

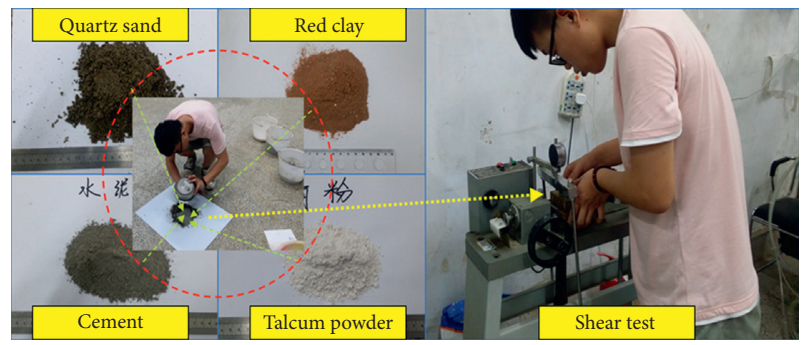

FIgURE 3: Similar material acquisition.

2.3. Design of the Loading Conditions. Since the response spectrum of the El-Centro seismic wave is in good agreement with the design response spectrum of the Chinese seismic code (Code for seismic design of buildings GB500112010), the El-Centro seismic wave was selected as the input wave for the shaking table test. Additionally, the seismic waves input in this test was all horizontal. When a $0.1 \mathrm{~g}$ seismic wave was loaded, the acceleration time history and frequency spectrum curve of the vibration table was collected, as shown in Figure 6. To meet the seismic design requirements of frequent, fortified, and rare earthquakes of the prototype area, the peak values of input waves were 0.1, $0.2,0.3$, and $0.4 \mathrm{~g}$, respectively. Additionally, to explore the failure mode of the tunnel model under extreme earthquakes, $0.6 \mathrm{~g}$ was designed and loaded, as presented in $\mathrm{Ta}-$ ble 4. Furthermore, to test the natural frequency of the model, a $0.2 \sim 50 \mathrm{~Hz}$ sine wave was inputted into the model before the start of the test to explore the initial dynamic characteristics of the model.

\section{Test Results}

3.1. Deformation and Failure Characteristics of the Model. The macroscopic test is the most intuitive means to analyze the deformation and failure of the model. During the entire process of the test from the beginning to the end, the subsequent loading continues to be loaded based on the previous working condition, without human intervention to restore the model to its original state. Therefore, the overall process of the model changes dynamically with the working conditions.
Through the observation of the deformation and failure process of the model, the failure process can be roughly divided into three stages: (1) in Case 1-2, the model has no obvious failure phenomenon; (2) in Case 3-4, the generation and development of cracks on the top of the slope and around the tunnel, named the deformation stage; and (3) in Case 5-6, the model has large deformation, name the failure stage.

When the amplitude of the seismic wave is $0.1 \mathrm{~g}$, there is no crack around the spatial parallel overlapped tunnel and the slope surface. With the increase of the input seismic amplitude, a slight transverse crack appears at the side wall of the upper-span tunnel in Case 2, as shown in Figure 7. Therefore, the model can be considered in the elastic stage in Case 1-2. Owing to the constraints of the surrounding rock on the tunnel structure, the soil-structure combination is relatively close, which is generally considered to be the structure with the best seismic performance; thus, the model is generally not prone to damage and deformation under the action of micro- and small earthquake loadings.

When the peak acceleration of the seismic wave is $0.2 \mathrm{~g}$ in Case 3 , the model has gradually begun to deform and destroy because the seismic inertia force and the amplitude of the input seismic wave increase. First, a transverse crack extending to the potential sliding surface appears at the top of the landslide slope. Then, some small cracks appear on the top and surface of the slope, which is dominated by transversal arc-shaped cracks. Additionally, cracks also appear in the intersection of the overlapped tunnel along the direction of the potential sliding surface. These phenomena are due to the horizontal tension caused by the horizontal seismic wave, which makes cracks on the top of the slope first. Furthermore, in Case 4, the existing cracks in the slope begin to spread and develop, and some new cracks appear near the potential sliding surface and the top of the slope, as shown in Figure 8. The occurrence and development of cracks indicate that local damage may have occurred in the surrounding rock at this time, resulting in enhanced absorption of seismic waves by the soil; thus, the model begins to enter the stage of deformation.

With the continuous increase of the input seismic wave amplitude, more notable model failure occurs. When the 


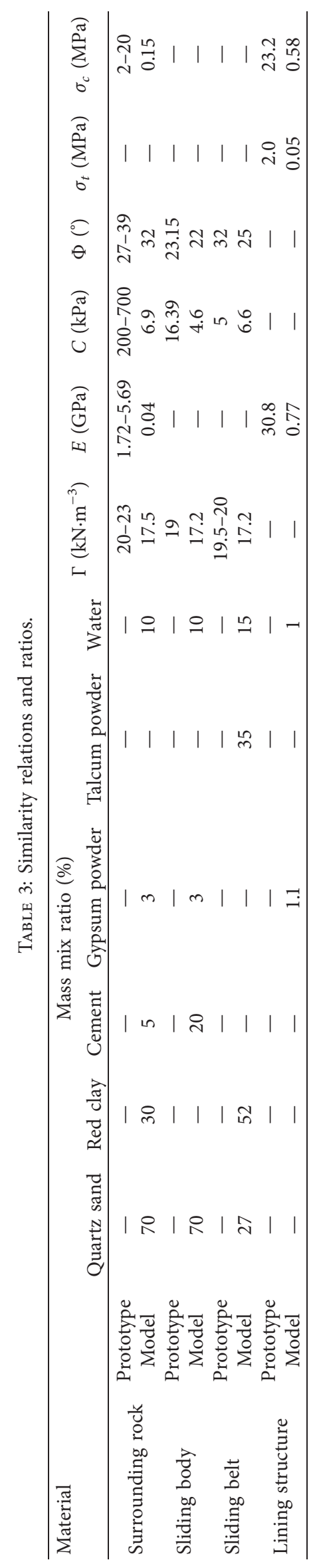




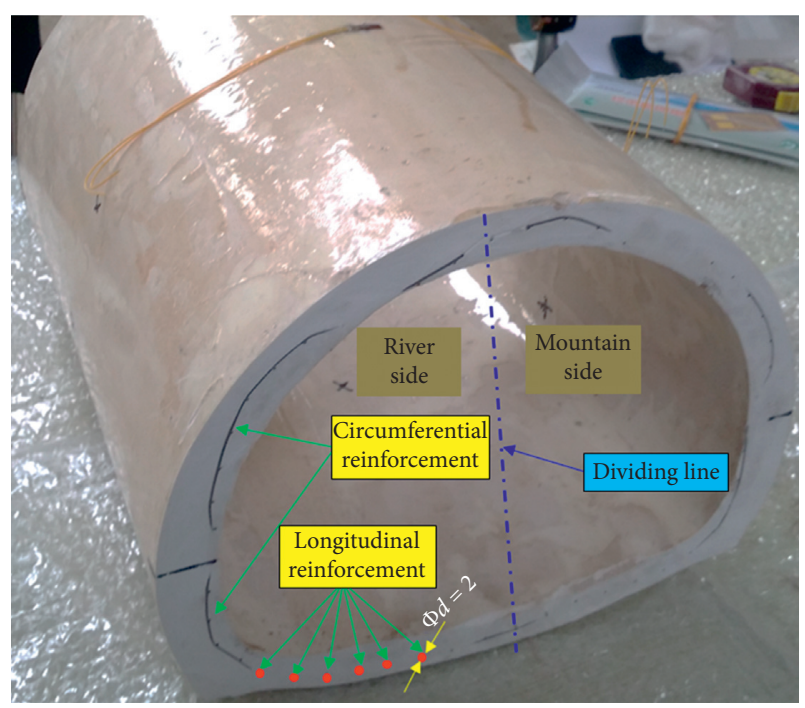

Figure 4: Tunnel model.

peak acceleration of loadings is 0.4 and $0.6 \mathrm{~g}$, the transverse cracks on the top and surface of the slope have penetrated. Owing to the consumption of seismic energy, the filtering effect of the surrounding rock is gradually intensified, leading to the gradual development of cracks. In Case 5, the cracks at the crown of the upper-span tunnel penetrate to the slope and "tore" the slope, causing a large amount of displacement. This occurs because that the stiffness of the surrounding rock and soil mass decreases and the damping ratio increases. Additionally, the cumulative damage of the model increases, indicating that the model is in the plastic strengthening stage of crack development. After loading the $0.6 \mathrm{~g}$ seismic wave, a large number of blocks at the place where the slope was pulled apart collapsed and slipped, and accumulated at the foot of the slope, as shown in Figure 9. The model has undergone major deformation and collapse and shows the characteristics of strong earthquake failure at the failure stage.

3.2. Damage of the Tunnel Lining. To clearly understand the dynamic strain changes and distribution laws of the tunnel lining in the circumferential direction under different seismic loading conditions, the dynamic strain peak value of the model is analyzed in the time domain, as shown in Figure 10.

The analysis of the peak dynamic strain on the outer surface of the upper-span tunnel lining shows that the peak strain at the crown $(S 1)$, the right arch waist $(S 2)$, the invert (S5), and the right side wall (S2) are larger, with the peak strain at the mountainside inverted arch being the largest, as shown in Figure 10(a). Moreover, the strain peaks at these four locations $(S 1, S 2, S 4$, and $S 5)$ form a "rectangle" and are parallel to the sliding direction of the slope, which also reveals the reason why the strain peaks at these four locations are larger. Figure 10(b) shows the peak dynamic strain on the inner surface of the upper-span tunnel lining. The inner surface of the lining shows the maximum tensile stress at the left arch waist $\left(S 6^{\prime}\right)$. In contrast, the right arch waist
$\left(S 2^{\prime}\right)$ shows the maximum compressive stress. The stress of the remaining parts is stable, and the difference in the peak dynamic strain under each case is small.

Figure 10(c) shows the peak dynamic strain on the outer surface of the under-crossing tunnel lining. When the seismic excitation is $0.1 \sim 0.3 \mathrm{~g}$, the difference between the peak values of dynamic strain at each point of the tunnel lining under various cases is small, and the entire tunnel gradually transits from a stable state to a small deformation stage. However, when the seismic excitation reaches $0.4 \mathrm{~g}$, the dynamic strain peak value of each measuring point changes drastically, which indicates that the slope of the under-crossing tunnel has structural damage at $0.4 \mathrm{~g}$. Additionally, from the point of view of the degree of change of the strain peak, the strain change of the crown (S7) is the most drastic, and the strain change of the right side wall (S9) is the most stable. This indicates that the under-crossing tunnel crown is likely to become a weak link in the seismic design. As seen from Figure 10(d), the peak dynamic strain is at the crown $\left(S 7^{\prime}\right)$, the right arch waist $\left(S 8^{\prime}\right)$, and the invert $\left(S 10^{\prime}\right)$ in the inner surface of under-crossing tunnel lining. Similar to the response of the outer surface lining, the strain peak value of each measuring point on the inner surface changes drastically in Cases 5 and 6.

By comparing the dynamic strain peak changes of the upper-span and under-crossing tunnel linings, it can be seen that for the upper-span tunnel, the peak strain of the tunnel lining (whether the inner surface or the outer surface) changes drastically after Case $3(0.2 \mathrm{~g})$. This indicates that the internal structure of the slope has changed after the input seismic amplitude of $0.2 \mathrm{~g}$, and the effect of seismic waves on the slope and tunnel reconstruction is enhanced. However, for the under-crossing tunnel, the strain peak of the tunnel lining changes drastically after Cases 5-6. This also shows that under the action of the seismic waves, the undercrossing is more stable than the upper-span tunnel. Note that this is also related to the changing form of the slope. From the previous test phenomenon, it can be inferred that the landslide is sliding. The trailing edge of the slope is damaged first, and then the sliding body slides down to exert a force on the lower slope and the tunnels.

Furthermore, the maximum stresses on the outer surface of the upper-span and under-crossing tunnel lining are both on the right arch waist $(S 2, S 8)$ and the left side wall $(S 5, S 11)$. However, the maximum stress on the inner surface of the upper-span and under-crossing tunnel linings is different. The upper-span tunnel appears at the left side of the arch $\left(S 6^{\prime}\right)$, whereas the under-crossing tunnel appears at the right arch waist $\left(S 8^{\prime}\right)$, the crown $\left(S 7^{\prime}\right)$, and the invert $\left(S 10^{\prime}\right)$. This phenomenon indicates that the forces on the inner and outer surfaces of the tunnel lining are different, and the right arch waist and the left side wall should be considered to be weak parts in the seismic design.

3.3. Dynamic Response of the Surrounding Rock. To clarify the seismic response distribution law of surrounding rock and tunnel crown and invert at the cross-center section, the acceleration response of the $A 1-A 6$ is analyzed. To more 


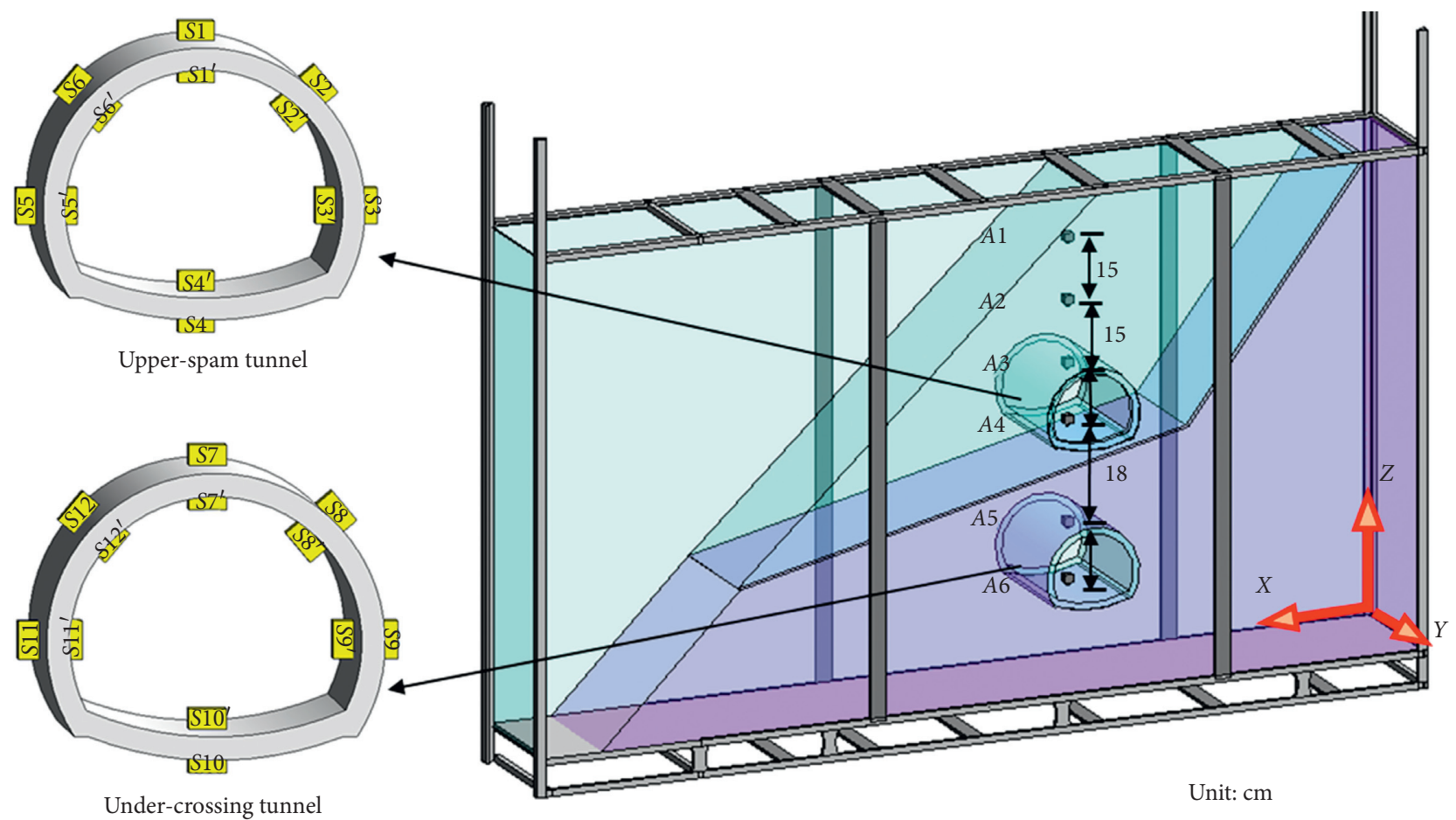

Under-crossing tunnel

Unit: $\mathrm{cm}$

\section{Strain gauge}

Acceleration sensor

(a)

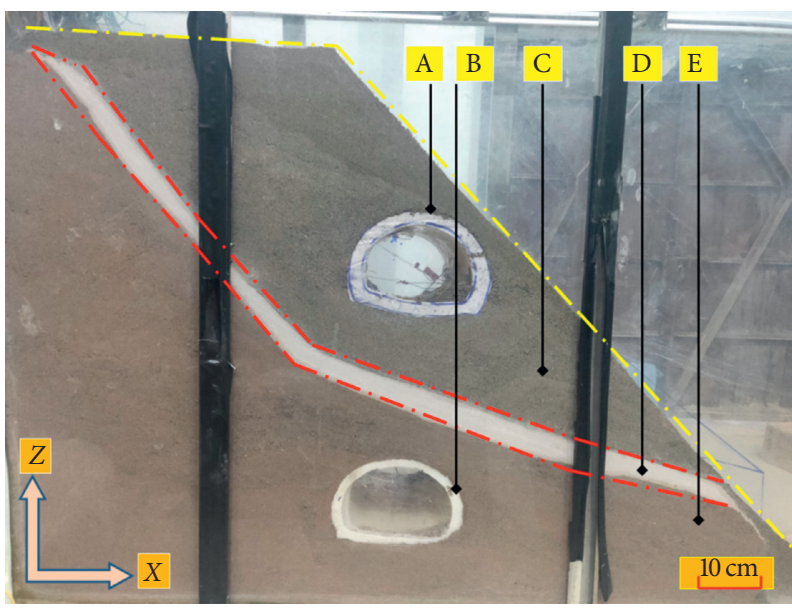

(b)

Figure 5: Arrangement of the sensors and layout of the model. A denotes the upper-span tunnel, B denotes the under-crossing tunnel, $\mathrm{C}$ denotes the slip body, D denotes the artificial boundary (potential sliding surface), and E denotes the surrounding rock. (a) Arrangement of the sensors. (b) The layout of the test model.

clearly explain the changing trend of the acceleration response of the tunnel structure and surrounding rock under different loading cases, the acceleration amplification factor is defined as the peak acceleration ratio of the measuring point under each case to the $0.1 \mathrm{~g}$ (Case 1), as shown in Figure 11.

The acceleration magnification coefficient of each measuring point along the elevation direction shows obvious regularity, which is an obvious magnification effect along the elevation. However, for the parallel overlapped tunnel, the acceleration response at the crown and invert of the tunnel is significantly different from that of a single-hole tunnel. Owing to the spatial effect and mutual influence of the intersection, the existence of the upper-span tunnel has a certain weakening of the seismic response of the undercrossing tunnel. This weakening effect is more obvious for the crown $(A 5)$ of the under-crossing tunnel.

Furthermore, the acceleration amplification factor has obvious stages. When the input seismic wave is $0.15-0.2 \mathrm{~g}$, the acceleration amplification factor of each measuring point 


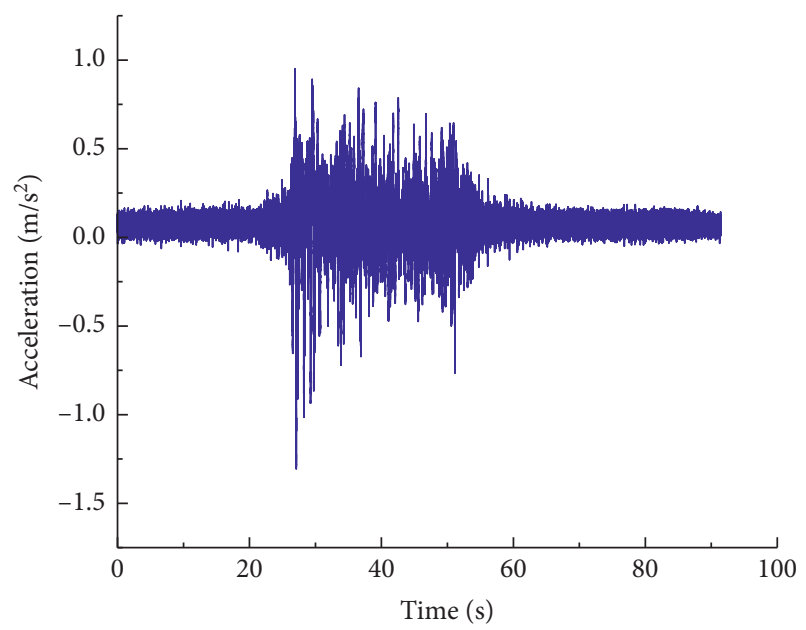

(a)

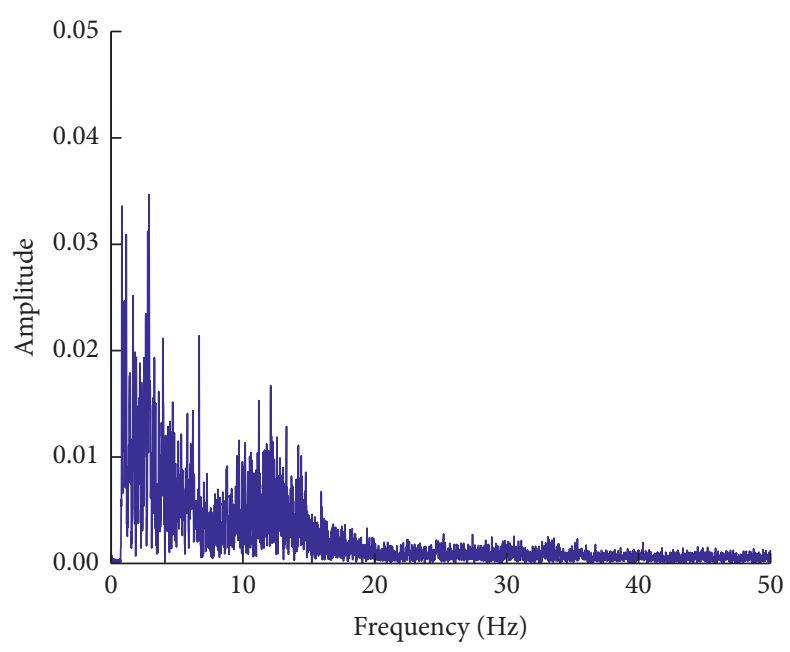

(b)

Figure 6: The curve of the time history and frequency spectrum of El-Centro. (a) Time history. (b) Fourier spectrum.

TABLE 4: Loading conditions.

\begin{tabular}{lccc}
\hline & Input motion & Direction & Peak acceleration $(g)$ \\
\hline Case 0 & Sine wave & $X$ & 0.05 \\
Case 1 & El-Centro & $X$ & 0.1 \\
Case 2 & El-Centro & $X$ & 0.15 \\
Case 3 & El-Centro & $X$ & 0.2 \\
Case 4 & El-Centro & $X$ & 0.3 \\
Case 5 & El-Centro & $X$ & 0.4 \\
Case 6 & El-Centro & $X$ & 0.6 \\
\hline
\end{tabular}

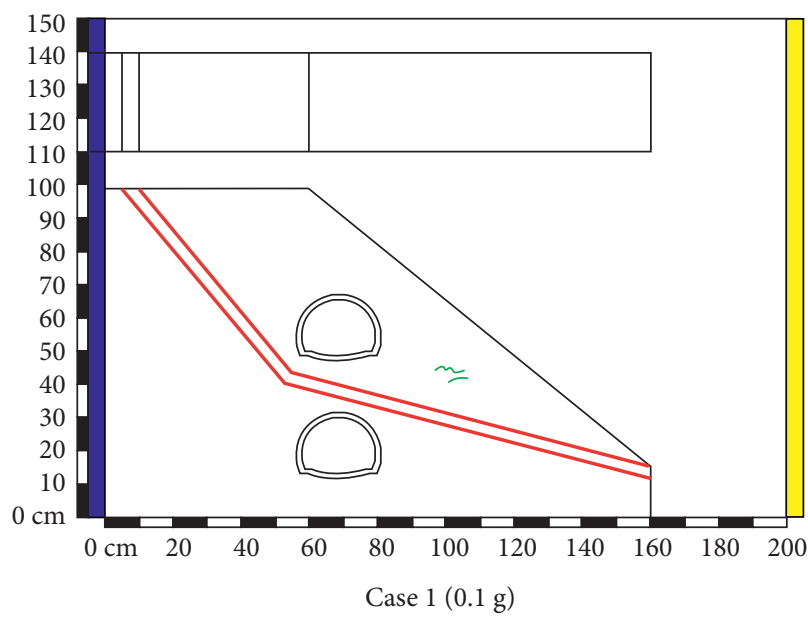

(a)

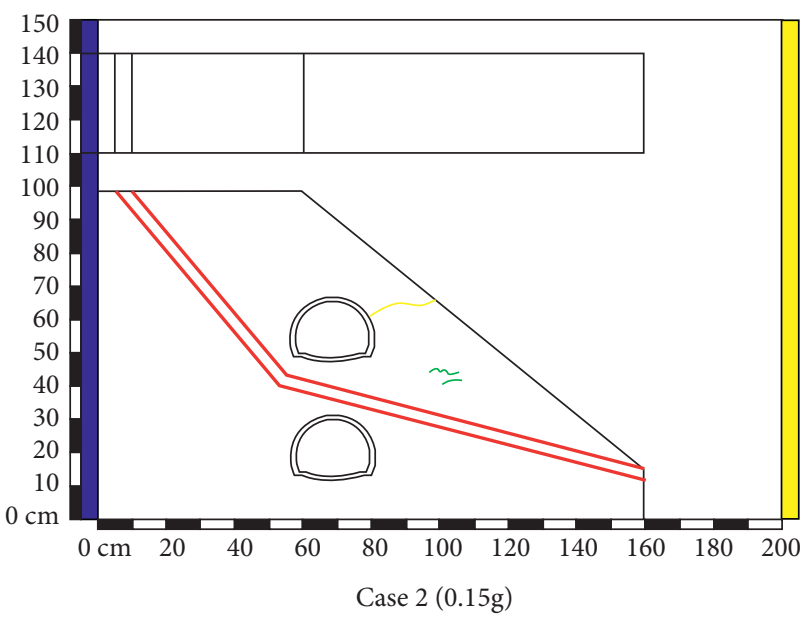

(b)

FIgure 7: Deformation and failure in Cases 1-2.

shows a linearly decreasing trend with the increase of the input amplitude of a seismic wave, indicating that the model is in an elastic state at this time. When the input seismic wave is $0.2-0.3 \mathrm{~g}$, the acceleration amplification factor gradually transits from the elastic characteristic to the plastic stage, and the acceleration amplification factor begins to increase, which indicates that the dynamic shear modulus of soil decreases and the damping ratio increases in this process.
When the input seismic wave is $0.3-0.4 g$, the acceleration amplification factor presents a "serrated" distribution state and cracks gradually increase. Moreover, the filtering effect becomes more intensified. These indicate that the model may be in the plastic enhancement stage. When the input seismic wave is $0.4-0.6 \mathrm{~g}$, the acceleration amplification factor has increased significantly, especially at the $A 1$ measurement point. This indicates that the slope top may 


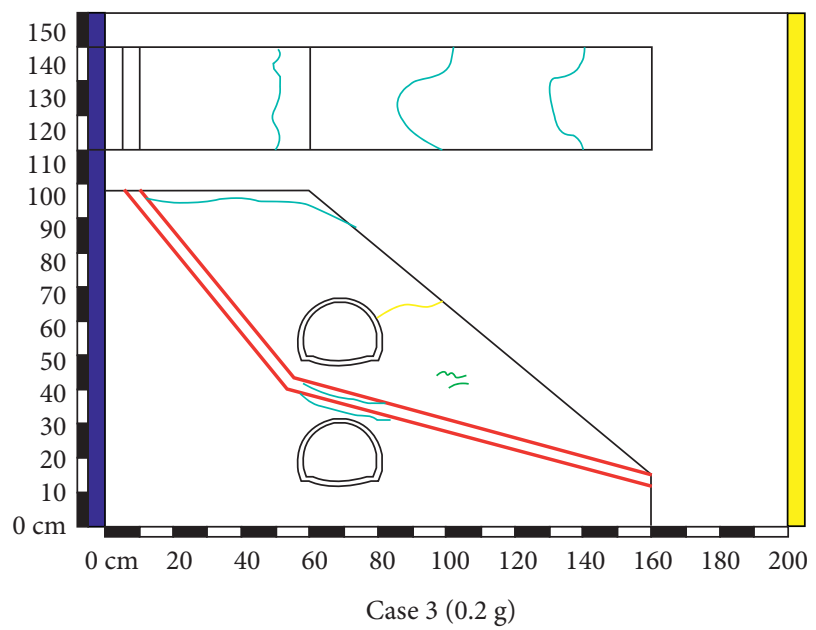

(a)

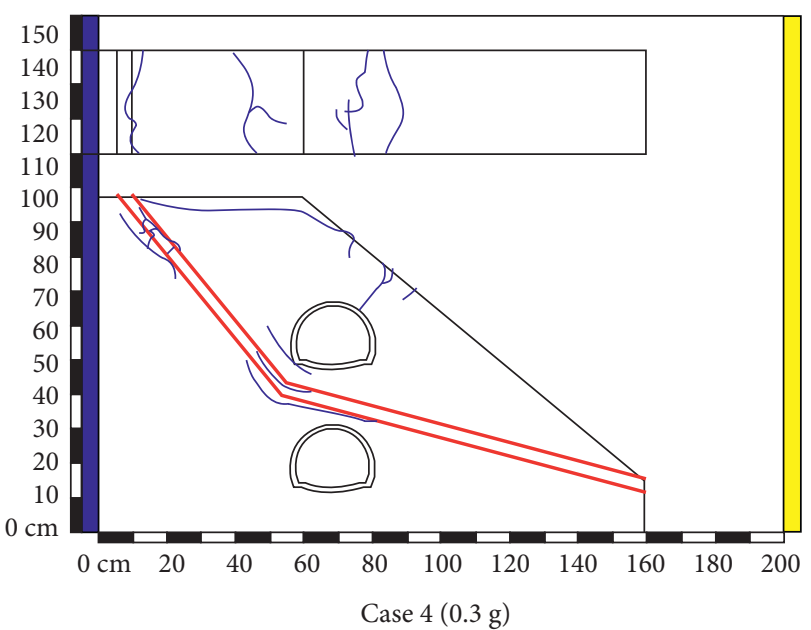

(b)

Figure 8: Deformation and failure in Cases 3-4.

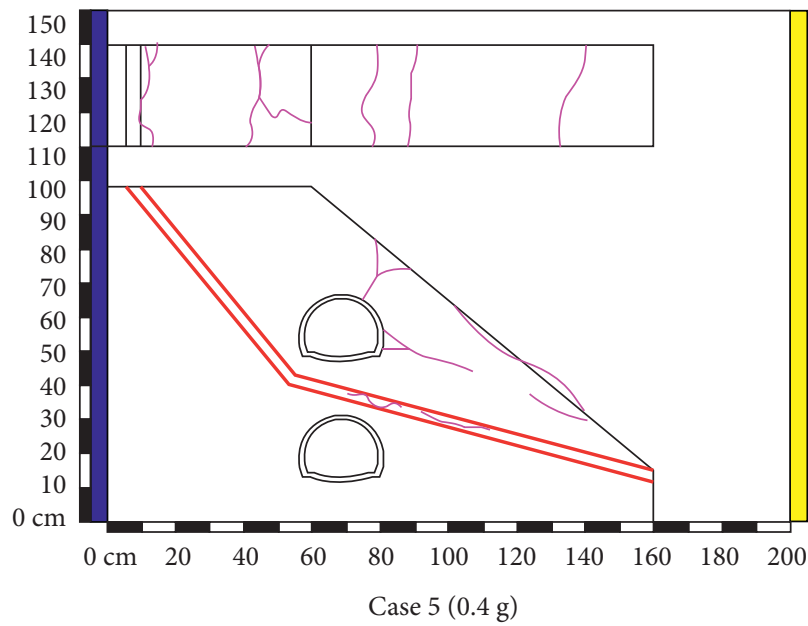

(a)

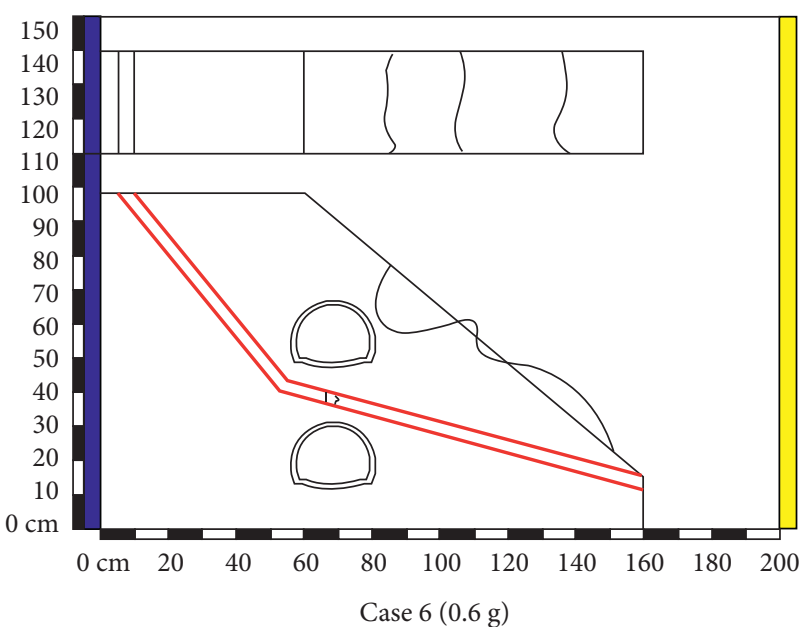

(b)

Figure 9: Deformation and failure in Cases 5-6.

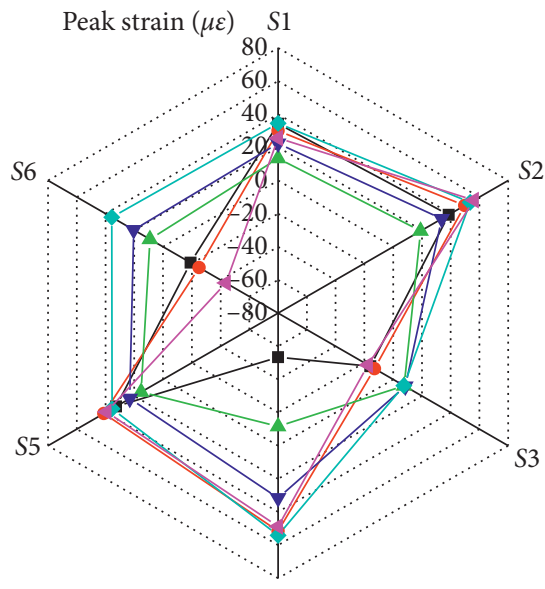

$S 4$

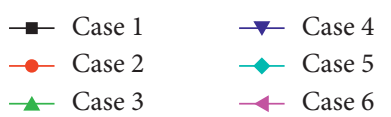

(a)

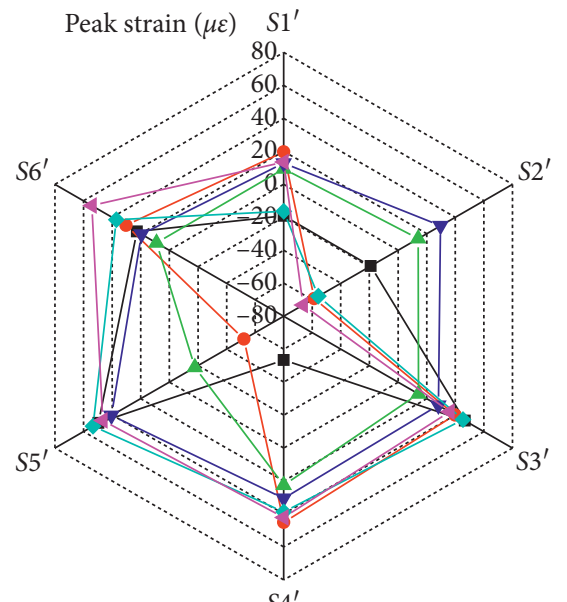

$S 4^{\prime}$

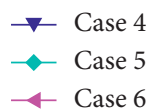

(b)
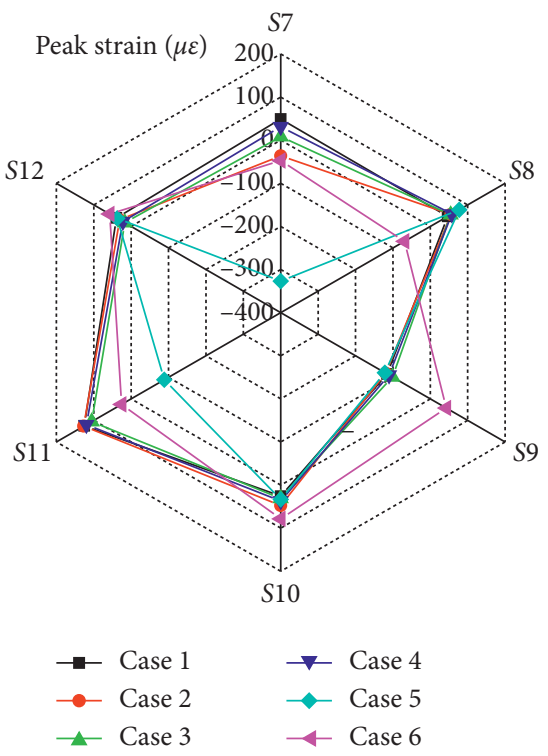

(c)

Figure 10: Continued. 


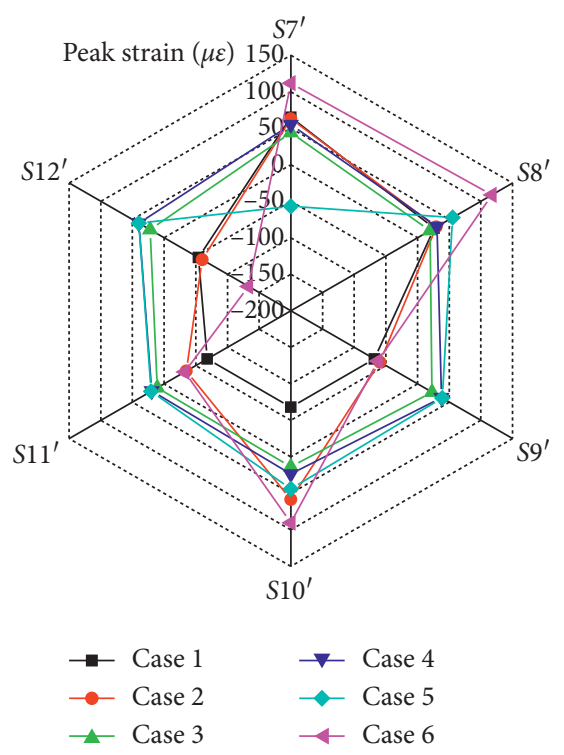

(d)

Figure 10: Damage of the tunnel lining. The strain gauge is tensioned as positive and compression is negative. (a) The outer surface of the upper-span tunnel. (b) The inner surface of the upper-span tunnel. (c) The outer surface of the under-crossing tunnel. (d) The inner surface of the under-crossing tunnel.

have loosened or even collapsed. Moreover, the integrity of the model has been destroyed, and its bearing capacity has been significantly weakened.

Through the above analysis, it is found that the model is basically in the critical failure stage in Case 5, so the acceleration response analysis is carried out with $0.4 \mathrm{~g}$ as an example. Figure 12 presents the acceleration time history curves of the $A 1-A 6$ in Case $5(0.4 \mathrm{~g})$. Under the action of $0.4 \mathrm{~g}$ seismic wave, the time of the peak acceleration of each measuring point is the same, which is about $30 \mathrm{~s}$. Additionally, as the height of the measuring points increases, the peak acceleration also increases. The peak acceleration values of $A 1-A 6$ are 8.07, 6.22, 4.63, 3.68, 2.72 , and $2.47 \mathrm{~m} / \mathrm{s}^{2}$, respectively, and the peak acceleration values are $1.30,1.34$, $1.26,1.35$, and 1.10 times of the latter, respectively. This also confirms that the overlapped tunnel structure has a certain amplification effect on seismic waves.

\section{Discussion}

4.1. Wavelet Packet Analysis. It is necessary to analyze the frequency spectrum to avoid the resonance of seismic waves with the structure in the main frequency band in engineering. Through analysis, we can obtain relevant information of excellent frequencies and frequency bands to understand the frequency and periodic distribution characteristics of the seismic wave propagation process more clearly and provide relevant theoretical references for engineering practice. Therefore, the wavelet packet analysis method is introduced to analyze the seismic energy and spectral characteristics of the intersection of the two tunnels.
To further subdivide the local characteristics of acceleration signal in the time domain and frequency domain, wavelet packet, which can reflect the characteristics of both frequency domain and time domain based on wavelet analysis [30], is used to analyze the ground motion response signal. The effective frequency range of the input seismic wave of the shaking table test is $0.1 \sim 50 \mathrm{~Hz}$, and the number of decomposition layers of the acceleration signal can meet the requirements by taking 3 layers considering the requirements of refinement and resolution. The analysis adopts the Meyer wavelet with good regularity, fast attenuation, and compact support in the frequency domain as the mother wavelet, and the acceleration signal is decomposed by discrete wavelet transform. The frequency band number and frequency range of the decomposed wavelet packet is shown in Figure 13.

Taking the $0.4 \mathrm{~g}$ acceleration response under Case 5 as an example, the wavelet packet transform method is used to analyze and change the upper-span tunnel invert $(A 4)$ and the under-crossing tunnel crown (A5), and the obtained acceleration response wavelet component diagrams in each frequency band are shown in Figure 14.

It is seen from Figure 14 that with the wavelet packet decomposition frequency band increases, the acceleration response gradually decreases, and the acceleration response of the first and second frequency bands is significantly larger than that of the other frequency bands. Furthermore, the main frequency bands that affect the acceleration response are the first frequency band wavelet component $(0.2 \sim 6.27 \mathrm{~Hz})$ and the second frequency band wavelet component $(6.27 \sim 12.52 \mathrm{~Hz})$, which also shows that the 


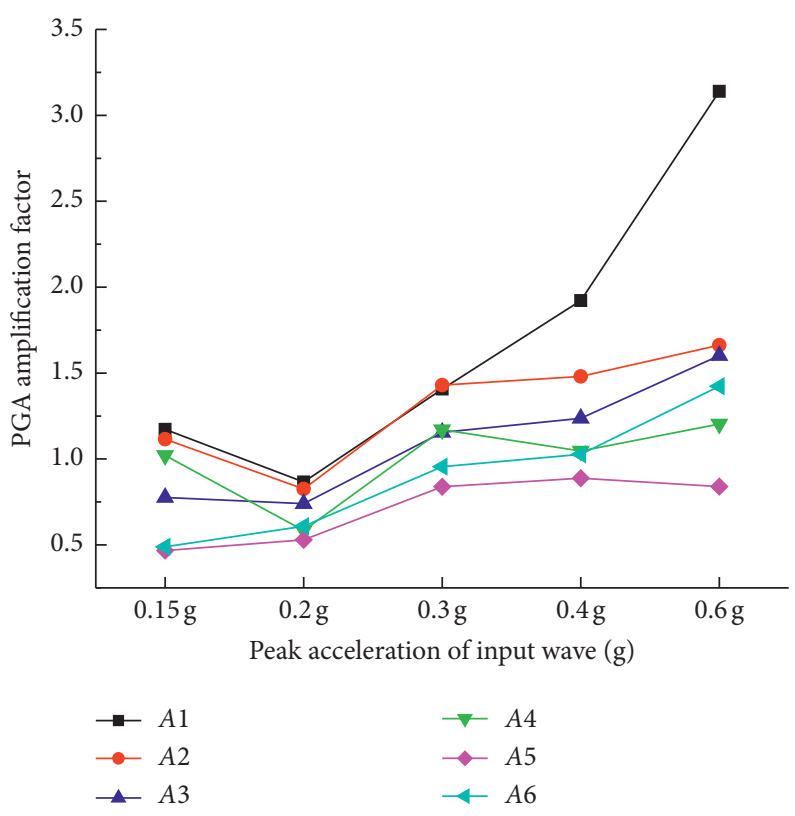

FIGURE 11: Distribution of acceleration amplification factor.

surrounding rock has a certain dissipation and filtering effect on the energy of seismic waves with medium and high frequency (above $12.52 \mathrm{~Hz}$ ). Additionally, it can be seen that after the wavelet packet decomposition of the acceleration response, the dynamic response of each frequency band at the $A 4$ is greater than that of the $A 5$, which indicates that the acceleration response may have a superposition effect at the invert of the upper-span tunnel.

4.2. Frequency Band Energy Ratio Analysis. It can be seen from Figure 13 that, in the shaking table test, the seismic waves in the 1st and 2 nd frequency bands $(0.2 \sim 6.27$ and $6.27 \sim 12.52 \mathrm{~Hz}$ ) play a major role in the three-dimensional crossing tunnel, but the proportion of seismic wave energy in each frequency band cannot be clearly expressed. To quantitatively reflect the proportion of seismic wave energy in the total energy in each frequency band, the MATLAB software is used to extract the energy characteristic values in each frequency band, as shown in Table 5 .

For the energy eigenvalues of each frequency band of the tunnel crown and invert, the energy eigenvalues of the 5th frequency band account for almost 0 in the total energy, indicating that the $25.02 \sim 31.27 \mathrm{~Hz}$ seismic wave has little effect on the crown and invert of the parallel overlapped tunnel. Except for $A 4$ under the action of $0.2 \mathrm{~g}$ and $0.4 \mathrm{~g}$ seismic waves, the energy eigenvalues of the 1st frequency band of all measuring points are more than $70 \%$ of the total energy under other cases. However, the energy eigenvalues of the 2nd frequency band vary significantly in the proportion of the total energy, and it can be obtained that under the action of seismic waves in the three cases, the average value of the energy characteristic of the 2 nd frequency band at each measurement point accounts for about $14.9 \%$ of the total energy. This also shows that the main effects on the crown and invert of the tunnel are the 1st frequency band $(0.2 \sim 6.27 \mathrm{~Hz})$ and the 2nd frequency band $(6.27 \sim 12.52 \mathrm{~Hz})$ seismic waves, and the 1st frequency band seismic wave plays a leading role.

When the peak value of the input wave is $0.2,0.4$, and $0.6 \mathrm{~g}$, the maximum sum of the energy eigenvalues of the 1 st and the 2 nd frequency band is $96.65 \%, 98.11 \%$, and $98.51 \%$, and the minimum is $94.70 \%, 89.66 \%$, and $88.84 \%$, respectively. With the increase of the peak value of the input wave, the proportion of the sum of the energy eigenvalues of the 1 st and the 2 nd frequency band to the total energy is increasing, which is caused by the gradual increase of the proportion of the energy eigenvalues of the 2nd frequency band. Furthermore, this shows that as the peak value of the input wave increases, the influence of the energy eigenvalue of the 1 st frequency band is gradually reduced, while the influence of the 2 nd frequency band is increasing.

For the sum of the energy eigenvalues of the 1st and 2nd frequency band seismic waves, the energy eigenvalues of the upper-span tunnel crown are all larger than those of the invert, while the energy eigenvalues of the undercrossing tunnel crown are gradually smaller than those of the invert with the increase of the seismic wave loading 


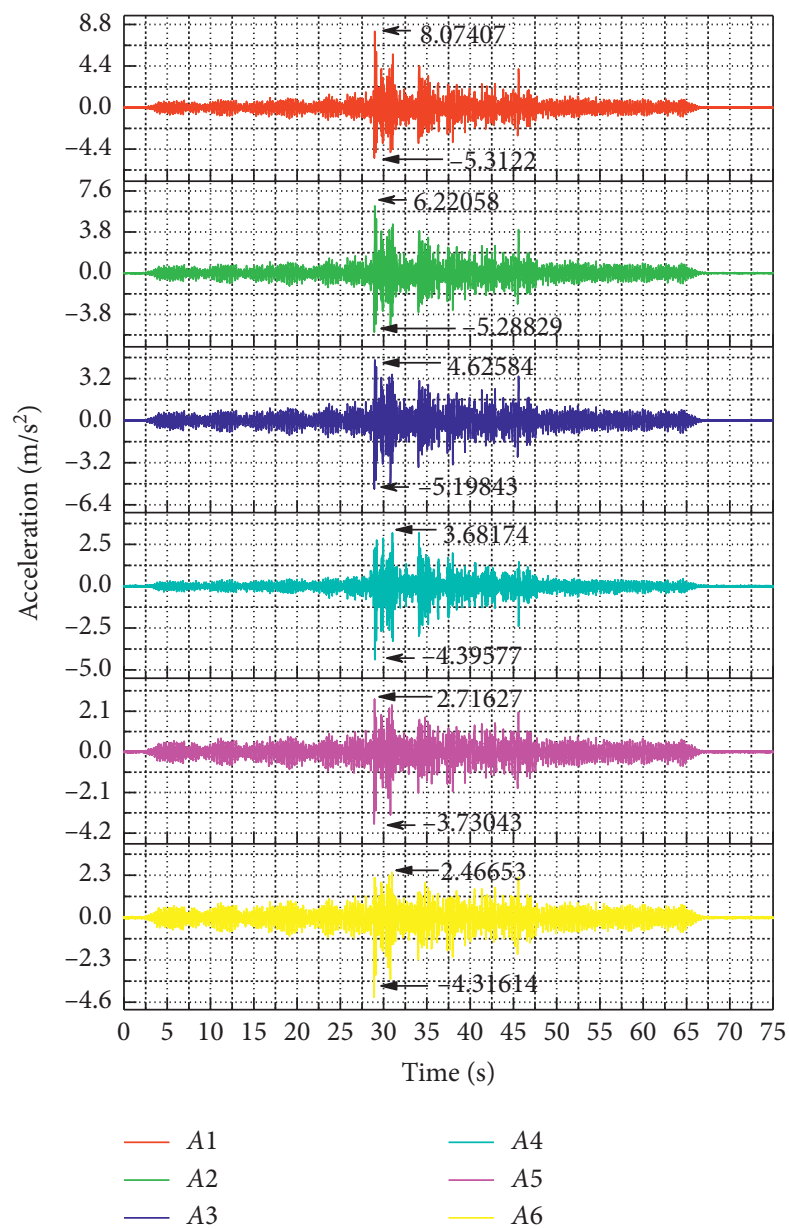

FIGURE 12: Time history of the acceleration of the central section under the action of $0.4 \mathrm{~g}$ seismic wave.

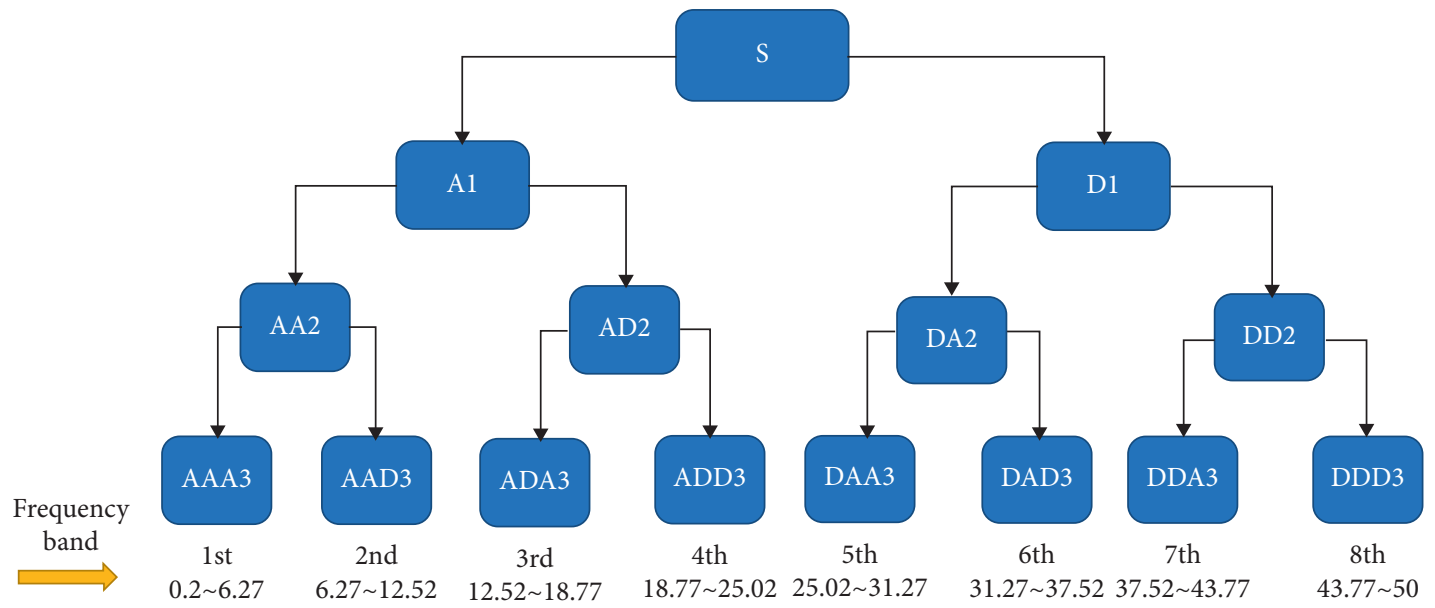

Figure 13: Decomposed wavelet packet frequency band number and frequency range. Note. $\mathrm{S}$ is the original input signal, $\mathrm{A}$ is an approximate signal, and D is the detailed signal (relatively high frequency). The width of each frequency band is $50 / 8=6.23 \mathrm{~Hz}$, and the corresponding lowest frequency band is $02 \sim 0.6 \mathrm{~Hz}$.

peak value. This phenomenon indicates that under the action of seismic loadings, the energy distribution characteristics of the upper-span and under-crossing tunnels are inconsistent, and the main weak position of the upperspan tunnel is the crown while the under-crossing tunnel is the invert. 

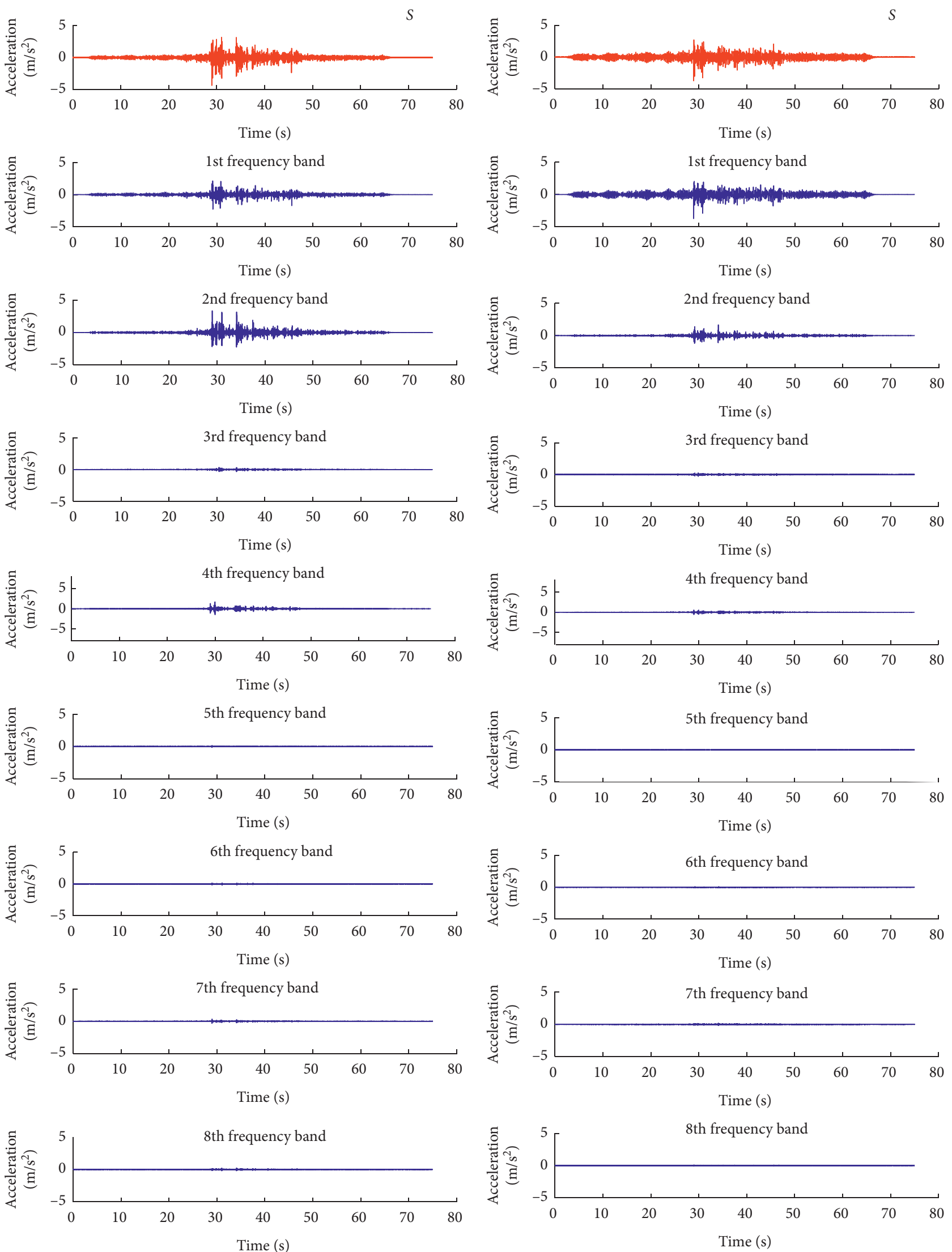

(a)

(b)

FIGURE 14: Wavelet component of acceleration response under the action of $0.4 \mathrm{~g}$ seismic wave. The red curve denotes the original dynamic acceleration time-domain curve, and the blue curves from top to bottom denote the wavelet components of the 1st to 8th frequency bands. (a) A4. (b) A5. 
TABLE 5: Acceleration energy ratio of the crown and invert under different amplitude seismic waves.

\begin{tabular}{lccccccccccccc}
\hline Monitoring point & \multicolumn{4}{c}{$0.2 g$} & \multicolumn{4}{c}{$0.4 g$} & \multicolumn{4}{c}{$0.6 \mathrm{~g}$} \\
& & $A 3$ & $A 4$ & $A 5$ & $A 6$ & $A 3$ & $A 4$ & $A 5$ & $A 6$ & $A 3$ & $A 4$ & $A 5$ & $A 6$ \\
\hline & $E 1$ & 79.71 & 80.60 & 89.94 & 77.33 & 78.10 & 48.14 & 87.16 & 89.96 & 74.33 & 48.93 & 80.52 & 83.56 \\
Energy ratio of each frequency band (\%) & $E 2$ & 16.94 & 14.10 & 6.67 & 18.58 & 19.64 & 40.70 & 10.28 & 8.55 & 22.83 & 40.73 & 16.47 & 14.55 \\
& $E 3$ & 0.65 & 0.79 & 0.67 & 1.51 & 0.67 & 1.36 & 0.60 & 0.55 & 0.81 & 1.26 & 0.78 & 0.65 \\
& $E 5$ & 1.53 & 2.79 & 1.08 & 1.22 & 1.28 & 8.77 & 1.45 & 0.52 & 1.58 & 7.99 & 1.78 & 0.83 \\
& $E 6$ & 0.43 & 0.60 & 0.57 & 0.06 & 0.02 & 0.05 & 0.02 & 0.01 & 0.02 & 0.05 & 0.02 & 0.02 \\
& $E 7$ & 0.29 & 0.43 & 0.54 & 0.99 & 0.18 & 0.33 & 0.35 & 0.33 & 0.23 & 0.43 & 0.29 & 0.27 \\
& $E 8$ & 0.39 & 0.61 & 0.56 & 0.17 & 0.07 & 0.42 & 0.10 & 0.05 & 0.12 & 0.37 & 0.09 & 0.06 \\
\hline
\end{tabular}

\section{Conclusion}

(1) The failure process of the model can be roughly divided into three stages, no obvious failure stage $(0.1 \sim 0.15 \mathrm{~g})$, deformation stage $(0.2 \sim 0.3 \mathrm{~g})$, and failure stage $(0.4 \sim 0.6 \mathrm{~g})$. First, the model appeared cracks on the crown of the upper-span tunnel, and the top of the slope and the intersection of the overlapped tunnel were damaged with the increase of the input seismic wave. Then, the cracks at the top of the upper-span tunnel penetrated and "tore" into the slope, causing a large amount of displacement. Finally, a large number of blocks at the place where the slope was pulled, collapsed and slipped, and the model was completely destroyed.

(2) According to the peak dynamic strain response of the tunnel, the lining damage on the outer surface of the upper-span and under-crossing tunnels mainly occurred on the right arch waist and the left side wall. Additionally, the lining damage on the inner surface of the upper-span tunnel was mainly reflected on the left arch waist, while the under-crossing tunnel was mainly manifested on the right waist arch, the crown, and the invert.

(3) For the parallel overlapped tunnel, the acceleration response at the crown and invert of the tunnel is significantly different from that of a single-hole tunnel. Owing to the spatial effect and mutual influence of the intersection, the existence of the upper-span tunnel has a certain weakening of the seismic response of the under-crossing tunnel, and this weakening effect is more obvious for the crown of the under-crossing tunnel.

(4) From energy eigenvalues of seismic waves, the main influences on the crown and invert of the tunnel were in the 1st frequency band $(0.2 \sim 6.27 \mathrm{~Hz})$ and the 2nd frequency band $(6.27 \sim 12.52 \mathrm{~Hz})$ seismic waves, and the 1 st frequency band seismic wave played a leading role. Furthermore, the energy distribution characteristics of the upper-span and under-crossing tunnels were inconsistent, and the main weak position of the upper-span tunnel was the crown while the under-crossing tunnel was the invert.

\section{Data Availability}

The data used to support the findings of this study are available from the corresponding author upon request.

\section{Conflicts of Interest}

The authors declare that there are no conflicts of interest regarding the publication of this article.

\section{Acknowledgments}

The authors gratefully acknowledge the financial support by the National Key R\&D Program of China (no. 2018YFC1504901), Natural Science Foundation of Gansu Province (no. 145RJZA068), Science and Technology Development Project of China Railway Research Institute Co. Ltd (2017-KJ008-Z008-XB), and Sichuan Provincial Science and Technology Plan Project (nos. 2021YFS0323, 2020YJ0253, and 2020YFSY0060).

\section{References}

[1] B. Yang, J. Hou, Y. Liu, and Z. Zhou, "Dynamic response and failure characteristics of slope with weak interlayer under action of near-fault ground motion," Shock and Vibration, vol. 2021, p. 18, Article ID 5595278, 2021.

[2] B. Yang, Z. Zhou, and L. Zhuo, "Experimental study on instability characteristic and bearing capacity of slope with bedrock under the action of rainfall," Journal of Southwest Jiaotong University, (in Chinese), 2020.

[3] M. S. Islam and M. Iskander, "Twin tunnelling induced ground settlements: a review," Tunnelling and Underground Space Technology, vol. 110, Article ID 103614, 2021.

[4] Y. Li, L. Peng, and M. Lei, "Research progress in the design and construction technology of crossing tunnels," Journal of Railway Science and Engineering, vol. 11, no. 1, pp. 67-73, 2014, in Chinese.

[5] C. Liu, L.-M. Peng, M.-F. Lei et al., "Research on crossing tunnels' seismic response characteristics," Korean Society of Civil Engineers, vol. 23, no. 11, 2019.

[6] H. Lei, H. Wu, Q. Meng et al., "Study on seismic dynamic response of oblique overlapped tunnels," Tunnel Construction, vol. 41, no. 1, p. 88, 2021, in Chinese.

[7] L. Kang, C. Shi, L. Peng et al., "Study on the influence factors of crossing tunnel based on orthogonal experiment," Journal of Railway Science and Engineering, vol. 9, no. 4, pp. 70-74, 2012, in Chinese. 
[8] M. Yin, H. Jiang, Y. Jiang, Z. Sun, and Q. Wu, "Effect of the excavation clearance of an under-crossing shield tunnel on existing shield tunnels," Tunnelling and Underground Space Technology, vol. 78, pp. 245-258, 2018.

[9] X. G. Li and D. J. Yuan, "Response of a double-decked metro tunnel to shield driving of twin closely under-crossing tunnels," Tunnelling and Underground Space Technology, vol. 28, pp. 18-30, 2012.

[10] H. Kuriyama, T. Koga, T. Ogata et al., "The design and construction of pillar reinforcement at horizontal twin tunnels," Journal of Tunnel Engineering JSCE, vol. 10, pp. 125-130, 2011.

[11] J. Gong, C. Xia, and X. Lei, “Analysis of field measurement and theoretical calculation on rock pressure in shallow-buried twin tunnels with small spacing," Chinese Journal of Rock Mechanics and Engineering, vol. 29, no. S2, pp. 4139-4145, 2010.

[12] B. Liu, Z. Yu, Y. Han, Z. Wang, R. Zhang, and S. Wang, "Analytical solution for the response of an existing tunnel induced by above-crossing shield tunneling," Computers and Geotechnics, vol. 124, Article ID 103624, 2020.

[13] Q. Lin, D. Lu, C. Lei, Y. Tian, Q. Gong, and X. Du, "Model test study on the stability of cobble strata during shield undercrossing," Tunnelling and Underground Space Technology, vol. 110, Article ID 103807, 2021.

[14] C. Zhang, X. Zhang, and Q. Fang, "Behaviors of existing twin subway tunnels due to new subway station excavation below in close vicinity," Tunnelling and Underground Space Technology, vol. 81, pp. 121-128, 2018.

[15] H. Y. Liu, J. C. Small, J. P. Carter, and D. J. Williams, "Effects of tunnelling on existing support systems of perpendicularly crossing tunnels," Computers and Geotechnics, vol. 36, no. 5, pp. 880-894, 2009.

[16] Q. Fang, D. Zhang, Q. Li, and L. N. Y. Wong, "Effects of twin tunnels construction beneath existing shield-driven twin tunnels," Tunnelling and Underground Space Technology, vol. 45, pp. 128-137, 2015.

[17] Y.-F. Jin, B.-Q. Zhu, Z.-Y. Yin, and D.-M. Zhang, "Threedimensional numerical analysis of the interaction of two crossing tunnels in soft clay," Underground Space, vol. 4, no. 4, pp. 310-327, 2019.

[18] Y. Li, L. Peng, and M. Lei, "Dynamics issues regarding highspeed railway crossing tunnels," Modern Tunnelling Technology, vol. 52, no. 2, pp. 8-15, 2015, in Chinese.

[19] H. Yi, T. Qi, W. Qian, Y. Yu, Y. Liu, Z. Li et al., "Influence of long-term dynamic load induced by high-speed trains on the accumulative deformation of shallow buried tunnel linings," Tunnelling and Underground Space Technology, vol. 84, pp. 166-176, 2019.

[20] Y. Xia, N. Jiang, C. Zhou, and X. Luo, "Safety assessment of upper water pipeline under the blasting vibration induced by Subway tunnel excavation," Engineering Failure Analysis, vol. 104, pp. 626-642, 2019.

[21] J. Lai, H. Fan, J. Chen et al., "Blasting vibration monitoring of undercrossing railway tunnel using wireless sensor network," Intermational Jourmal of Distributed Sensor Networks, vol. 2015, pp. 1-9, 2015.

[22] H.-B. Zhao, Y. Long, X.-H. Li, and L. Lu, "Experimental and numerical investigation of the effect of blast-induced vibration from adjacent tunnel on existing tunnel," KSCE Journal of Civil Engineering, vol. 20, no. 1, pp. 431-439, 2016.

[23] X. Zhang, Zhoushunhua, C. He et al., "Experimental Investigation on train-induced vibration of the ground railway embankment and under-crossing subway tunnels," Transportation Geotechnics, vol. 26, Article ID 100422, 2020.

[24] W. Yang, C. Zhang, D. Liu, Q. Yan, Y. Fang, C. He et al., "The effect of cross-sectional shape on the dynamic response of tunnels under train induced vibration loads," Tunnelling and Underground Space Technology, vol. 90, pp. 231-238, 2019.

[25] T. Grigorios, S. Filomena de, A. Ioannis et al., "Seismic behaviour of tunnels: from experiments to analysis," Tunnelling and Underground Space Technology, vol. 90, Article ID 103334, 2020.

[26] H. Lei, H. Wu, and T. Lai, "Shaking table tests for seismic response of oblique overlapped tunnel," Shock and Vibration, vol. 2021, Article ID 8816755, 19 pages, 2021.

[27] H. Wu, H. Lei, and T. Lai, "Shaking table tests for seismic response of orthogonal overlapped tunnel under horizontal seismic loading," Advances in Civil Engineering, vol. 2021, Article ID 6633535, 19 pages, 2021.

[28] T. Zhang, B. Gao, K. Fan et al., "Study on flexible material in the sidewall of rigid model box in shaking table test," Chinese Journal of Rock Mechanics and Engineering, vol. 37, no. 10, pp. 2415-2424, 2018, in Chinese.

[29] H. Wu, X. Chen, and A. Hui, "Research on the force exerting mode model test of tunnel-landslide orthogonal system," Journal of Railway Engineering Society, vol. 33, no. 3, pp. 1-28, 2016, in Chinese.

[30] A. Grinsted, J. C. Moore, and S. Jevrejeva, "Application of the cross wavelet transform and wavelet coherence to geophysical time series," Nonlinear Processes in Geophysics, vol. 11, no. 56, pp. 561-566, 2004. 